University of Nebraska - Lincoln

DigitalCommons@University of Nebraska - Lincoln

1991

\title{
Leaf Reflectance and Transmittance in Soybean and Corn
}

\author{
Elizabeth A. Walter-Shea \\ University of Nebraska - Lincoln, ewalter-shea1@unl.edu \\ Blaine Blad \\ University of Nebraska - Lincoln
}

Follow this and additional works at: https://digitalcommons.unl.edu/natrespapers

Part of the Natural Resources and Conservation Commons, Natural Resources Management and Policy Commons, and the Other Environmental Sciences Commons

Walter-Shea, Elizabeth A. and Blad, Blaine, "Leaf Reflectance and Transmittance in Soybean and Corn" (1991). Papers in Natural Resources. 1173.

https://digitalcommons.unl.edu/natrespapers/1173

This Article is brought to you for free and open access by the Natural Resources, School of at DigitalCommons@University of Nebraska - Lincoln. It has been accepted for inclusion in Papers in Natural Resources by an authorized administrator of DigitalCommons@University of Nebraska - Lincoln. 


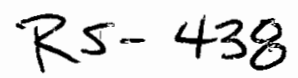

\title{
Leaf Reflectance and Transmittance in Soybean and Corn
}

\author{
E. A. Walter-Shea, ${ }^{*}$ J. M. Norman, B. L. Blad, and B. F. Robinson
}

\begin{abstract}
Leaves have a major influence on canopy reflectance when they constitute the main spatial component in a vegetative canopy. Near normal-incidence, directional-hemispherical reflectance and transmittance of in situ individual leaves of soybean (Glycine max., Merr.) and corn (Zea mays, L.) were characterized as a function of wavelengths and growth. Spectral properties were measured in seven wavebands with an integrating sphere and prototype radiometer unit. Individual leaves periodically were monitored from emergence and unfolding through $47 \mathrm{~d}$ in soybean and $77 \mathrm{~d}$ in corn. Visible reflectance and transmittance decreased in soybean as leaves expanded, but increased after full leaf expansion. An opposite pattern was observed with soybean near-infrared radiation (NIR) reflectance. Spectral properties varied little in mid- and upper-canopy corn leaves with the exception of the green spectral region. Near constant values were attributed to the fact that corn leaves are fully expanded by the time they have fully emerged. Reflectance and transmittance properties of adaxial and abaxial surfaces differed by as much as an absolute $5 \%$ in soybeans while there were essentially no differences in corn. Differences in surface reflectance and transmittance in soybean were attributed to the dorsiventral morphology of soybean leaves. Reflectance and transmittance from adaxial and abaxial leaf surfaces may have to be considered in modeling soybean canopies while one surface should suffice to describe light interaction with corn canopy leaves.
\end{abstract}

L

EAVES are the primary scattering units in a vegetative canopy. Radiant energy incident on a leaf can be scattered from the leaf surface into or away from the leaf, giving rise to specularly reflected and diffusely reflected and transmitted radiation. Radiant energy also will be absorbed by the leaf. Partitioning of radiation is a function of leaf cellular structure (Gates et al., 1965; Knipling. 1970; Gausman et al.,

E.A. Walter-Shea and B.L. Blad, Dep. of Agricultural Meteorology, 239 Chase Hall, Univ. of Nebraska, Lincoln, NE 68583-0728; J.M. Norman, Dep. of Soil Science, 1525 Observatory Dr.. Univ. of Wisconsin, Madison, WI 53706: and B.F. Robinson, Dep. of Elect. Eng.. Purdue Univ., W. Lafayette, IN 47907. Published as Paper no. 9399. J. Ser. Nebraska Agric. Res. Div. Received 23 Oct. 1989. *Corresponding author

Published in Agron. J. 83:631-636 (1991).
1970; Woolley, 1971), leaf surface coatings and roughness (Gausman, 1977; Grant et al., 1987), and morphological and physiological parameters (Gausman et al., 1971a,b; Gausman and Allen, 1973). Leaf anatomical structure and biochemical composition are critical to the amount of radiation absorbed, transmitted, or reflected.

Relatively little incident visible radiation $0.35-0.7$ $\mu \mathrm{m})$ is reflected or transmitted in healthy green leaves due to absorption by chlorophyll and other leaf pigments (Gausman, 1982; Maas and Dunlap, 1989). Decreased visible reflectance with leaf development and maturation in cotton (Gossypium hirsutum L.) (Gausman et al., 1970), white oak (Quercus alba L.) (Gates et al., 1965) and apple (Malus domestica Borkh.) (Palmer, 1977) have been attributed to pigment accumulation. In contrast, leaves absorb relatively little incident near-infrared (NIR) ${ }^{1}$ radiation $(0.75-1.35$ $\mu \mathrm{m}$ ) because NIR scattering by the leaf mesophyll results in high reflectance and transmittance. Any change in the internal leaf structure will ultimately affect NIR properties. Near-infrared radiation reflectance was less in younger than in older cotton leaves with little difference in visible reflectance (Gausman et al., 1970).

The objective of this research was to characterize directional-hemispherical reflectance and transmittance properties at near-normal incidence of individual in situ soybean and corn leaves as a function of wavelength and leaf growth.

\section{MATERIALS AND METHODS}

Data were acquired in soybean and corn during 1984 at the University of Nebraska Sandhills Agricultural Laboratory $\left(41^{\circ} 37^{\prime} \mathrm{N}, 10^{\circ} 50^{\prime} \mathrm{W}\right.$ and $975 \mathrm{~m}$ above mean sea level), $70 \mathrm{~km}$ north of North. Platte, NE. Soybean was planted at 32.8 plants $\mathrm{m}^{-2}$ in north-south rows with a row spacing of $0.76 \mathrm{~m}$. 'Corsoy' soybean was irrigated at $100 \%$ (wellwatered) or $33 \%$ (water-stressed) soil moisture replacement.

\footnotetext{
'Abbreviations: NIR, near-infrared radiation: TM, Landsat Thematic Mapper: DOY, day of year: RLG, relative leaflet growth; and LA, leaflet area
} 


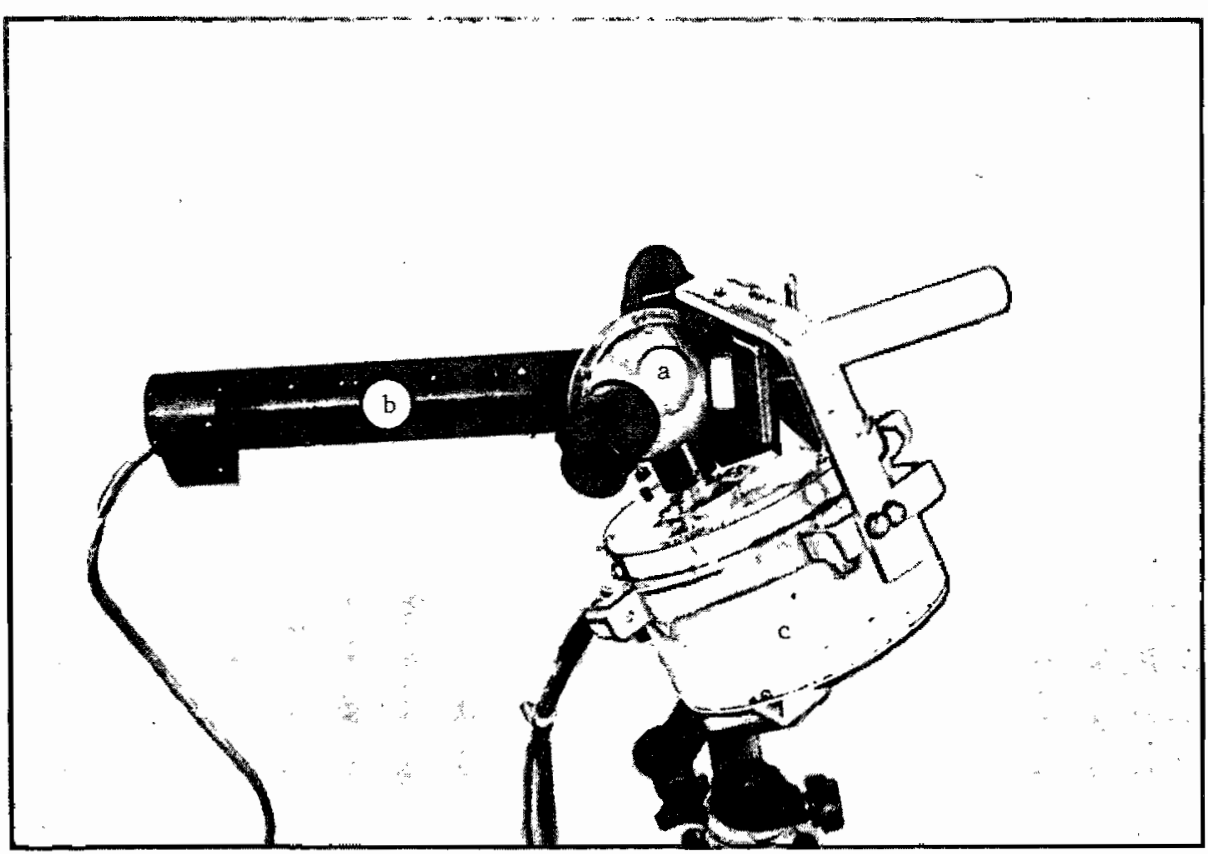

Fig. 1. A photograph of (a) the LI-COR Integrating Sphere Model 1800-12 and (b) LI-COR 1800-12B Illuminator attached to (c) the prototype radiometer.

Soil moisture loss was determined using a Troxler Model 3222 Moisture Depth Gauge ${ }^{2}$ (Troxler Electronic Laboratories, Inc., Research Triangle, NC 27709).

Pioneer 3901 corn was planted at 7.3 plants $\mathrm{m}^{-2}$ in northsouth rows with a row spacing of $0.76 \mathrm{~m}$. The corn was irrigated at $100 \%$ soil water replacement (well-watered) treatment only.

Reflectance and transmittance of individual soybean leaflets and corn leaves were measured in situ with a LI-180012 Integrating Sphere (LI-COR, Inc., Lincoln, NE 68504) attached to a prototype field-portable radiometer (Fig. 1) (Mesarch et al., 1991). The integrating sphere included a light source power supply, (LI-COR 1800-12B Illuminator), a pressed barium sulfate $\left(\mathrm{BaSO}_{4}\right)$ reference standard, and sample chamber to hold the leaf. The light source, a $6 \mathrm{~V}, 10 \mathrm{~W}$ glass halogen lamp, provided a collimated beam with $<5 \%$ stray light. Three apertures on the sphere allowed the lamp to be positioned for reference, reflected, or transmitted radiation measurements. The light source was mounted across from the pressed $\mathrm{BaSO}_{4}$ standard for reference readings, across from the sample for reflected, and directly behind the sample for transmitted light readings. The leaf, external to the sphere, was placed in the sample chamber, completing the sphere interior. The leaf portion in the sample chamber was directly illuminated when the lamp was positioned for reflected or transmitted light readings. Reflected or transmitted radiation was diffusely reflected from the painted $\mathrm{BaSO}_{4}$ coating of the wall, which uniformly illuminated the sphere by internal reflectance and resulted in a good approximation to directional-hemispherical reflectance and transmittance factors at near-normal incidence.

Radiation in the integrating sphere exited through the sensor port to the attached radiometer and produced an analog voltage response to the radiant energy from the sphere. Voltage was proportional to the amount of radiant energy in the sphere reflected from or transmitted through the leaf sample. The detector did not view any part of the sample; the field of view was occupied by the sphere wall. Seven narrow-pass radiometer filters were used. All filters, except Waveband 5 $(1.15-1.30 \mu \mathrm{m})$, corresponded to the Landsat Thematic Mapper (TM) wavebands (Table 1). Response measurements

\footnotetext{
${ }^{2}$ The use of trade names does not imply endorsement of the products by the authors.
}

from surfaces of known transmittance varied most with Waveband 7; this waveband was excluded from the analysis. Output (volts proportional to the flux) was recorded on an Omnidata Polycorder (Omnidata Inc., P.O. Box 3489, Logan, UT 84321).

Measurements were made on intact abaxial (lower) and adaxial (upper) surfaces of individual soybean leaflets and corn leaves. Measurements were made intermittently from leaflet unfolding or leaf emergence through $47 \mathrm{~d}$ in soybean and $77 \mathrm{~d}$ in corn, twice daily when possible.

Stray light due to an imperfectly collimated beam and the dark current response (integrating sphere not illuminated) were measured periodically. Output from the instrument was corrected for stray light and dark current responses.

\section{Calculations of Reflectance and Transmittance}

Reflectance $\left(\rho_{k}\right)$ of leaves was calculated as the ratio of voltage equivalence of reflected radiation from the sample surface for Waveband $\mathrm{k}\left(E_{\mathrm{r}, \mathrm{k}}\right)$ to the voltage equivalence of reflected radiation from the standard for Waveband $\mathrm{k}\left(E_{\text {ref, } \mathrm{k}}\right)$. Both were corrected for dark current readings $\left(E_{\mathrm{d}(r), \mathrm{k}}\right.$ and $\left.E_{\mathrm{d}(\mathrm{ren}, \mathrm{k}}\right)$ associated with each waveband and reading time, and for stray light $\left(E_{\mathrm{s}, \mathrm{k}}\right)$ and associated dark current reading $\left(E_{\mathrm{d}(\mathrm{s}) \mathrm{k}}\right)$ as follows:

$$
\rho_{\mathrm{k}}=\frac{\left[E_{\mathrm{r}, \mathrm{k}}-E_{\mathrm{d}(\tau), \mathrm{k}}-\left(E_{\mathrm{s}, \mathrm{k}}-E_{\mathrm{d}(\mathrm{s}), \mathrm{k}}\right)\right]}{\left[E_{\mathrm{ref}, \mathrm{k}}-E_{\mathrm{d}(\mathrm{ref}), \mathrm{k}}-\left(E_{\mathrm{s}, \mathrm{k}}-E_{\mathrm{d}(\mathrm{s}), \mathrm{k}}\right)\right]} \cdot \rho_{\mathrm{ref}, \mathrm{k}}
$$

where $\rho_{\text {ref, }}$ represents a correction for the non-perfect reflector property of the pressed $\mathrm{BaSO}_{4}$ standard of the integrating sphere.

Transmittance $\left(\tau_{k}\right)$ of leaves for each Waveband $k$ was computed similarly:

$$
\tau_{\mathrm{k}}=\frac{\left[E_{\mathrm{l}, \mathrm{k}}-E_{\mathrm{d}(\mathrm{t}) \mathrm{k}}\right]}{\left[E_{\mathrm{ref}, \mathrm{k}}-E_{\mathrm{d}(\mathrm{ref}, \mathrm{k}}-\left(E_{\mathrm{s}, \mathrm{k}}-E_{\mathrm{d}(\mathrm{s}), \mathrm{k}}\right)\right]} \cdot \rho_{\mathrm{ref}, \mathrm{k}}
$$

\section{Soybean}

Directional-hemispherical reflectance and transmittance of abaxial and adaxial surfaces at near-normal incidence of intact field-grown soybean leaflets were monitored from the time of leaflet unfolding (average day of year [DOY] 208) to the end of the experiment at which time leaf yellowing 
Table 1. Spectral bands measured with the integrating sphere/radiometer arrangement and the Barnes Model 12-1000 Modular Multiband Radiometer (MMR). TM refers to Thematic Mapper wavebands.

\begin{tabular}{cc}
\hline Waveband & Wavelengths \\
\hline & $\mu \mathrm{m}$ \\
1 TM1 & $0.45-0.52$ \\
2 TM2 & $0.52-0.60$ \\
3 TM3 & $0.63-0.69$ \\
4 TM4 & $0.76-0.90$ \\
$5---$ & $1.15-1.30$ \\
6 TM5 & $1.55-1.75$ \\
7 TM7 & $2.08-2.35$ \\
\hline
\end{tabular}

was visually detected (DOY 254). Measurements were initiated when terminal trifoliate leaflets were greater than 15 $\mathrm{mm}$ in width, since the integrating sphere sample chamber prevented use of smaller leaflets. Thus, the relative portion of the leaflet sampled for measurement varied during growth. Initial measurements included most of the leaflet area due to the small size of leaflets. The lower and wider part of the terminal leaflet was sampled as the leaflet grew and approached full expansion to avoid the leaflet midrib. Leaflet area was approximated from length and maximum width measurements made at the beginning of each day of leaflet reflectance and transmittance measurements to provide a general indicator of leaflet growth and expansion (Ross, 1981). Relative leaflet growth (RLG), an indicator of leaflet growth, was calculated as the ratio of estimated leaflet area at the time of optical measurements (LA) to the maximum leaflet area achieved during the experiment $\left(\mathrm{LA}_{\max }\right)$, such that $\mathrm{RLG}=\mathrm{LA} / \mathrm{LA}_{\max }$.

Leaflet reflectance and transmittance data were obtained twice daily when possible from both abaxial and adaxial leaflet surfaces from nodal Positions 10 and 11 (considering the unifoliate leaf position to be Node 1) from two plants in well-watered and water-stressed plots. There was no significant difference of optical properties between morning and afternoon for most wavebands (transmittance through corn and soybean adaxial leaf surfaces was significantly different at 0.10 for Band 6). Data for all times of day were pooled so that plotted values represent the mean of four to eight leaflet measurements.

\section{Corn}

Directional-hemispherical reflectances and transmittances were measured on corn leaves from node Positions 11, 12, 16 , and 17 . Replicated reflectance and transmittance properties of Leaves 11 and 12 and of Leaves 16 and 17 were averaged to represent mid- and upper-canopy leaves, respectively.

Optical properties of abaxial and adaxial surfaces of intact leaves on two plants were measured at near-normal incidence from leaf tip emergence (average DOY 178 of the midcanopy leaves) to the end of the experiment (DOY 254). Three leaf positions, representing a chronological sequence of leaf emergence, were selected for measurement. The first measurement position represented the leaf surface generally exposed the second day after leaf tip emergence. The second measurement position represented leaf surfaces generally exposed after the fifth day of leaf tip emergence and the third measurement position represented leaf surfaces exposed when the leaf approached full emergence. All positions were monitored until full leaf emergence, but subsequently, only the second position (about mid-leaf) was monitored for the remainder of the experiment.

\section{RESULTS AND DISCUSSION}

\section{Leaf Spectral Properties}

Soybean. Relative leaflet growth of water-stressed and well-watered soybean leaflets did not differ signif-

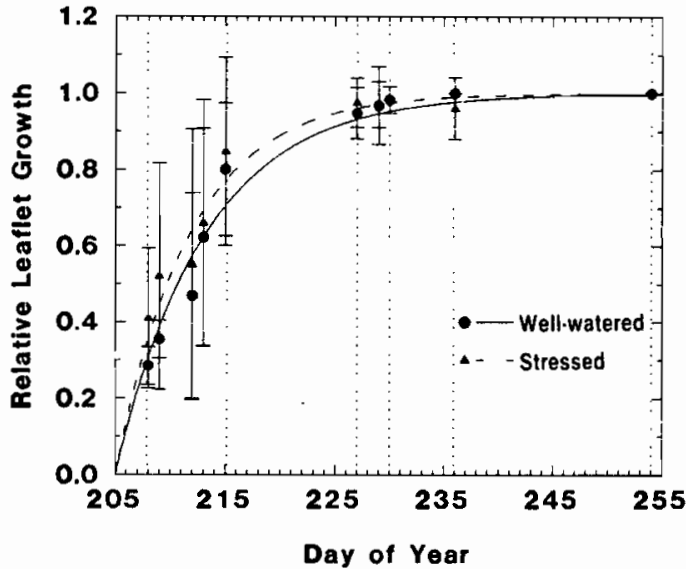

Fig. 2. Mean relative leaflet growth of four well-watered (solid circle, line) and four water-stressed soybean leaflets (solid triangle, dashed) throughout the experimental period. Relative leaf growth is the ratio of an approximate leaflet area at the time of reflectance measurements to the average maximum leaflet area achieved during the experimental period. Vertical dashed lines indicate days for which soybean leaflet optical properties are presented. Error bars represent \pm 1 standard deviation.

icantly (Fig. 2). Vascular and mesophyll tissues are well established at the time leaflet unfolding commences but cells comprising these tissues are immature (Dale and Milthorpe, 1983). Cell division ceases first in the epidermis then shortly afterward in the spongy mesophyll (Decker and Postlethwait, 1961). Cell enlargement follows in these tissues while cell division and expansion continues in the palisade layer. Expansion continues as the leaf approaches full size. Average RLG estimates at DOY 230 (approximately 3 wk after initial measurement) indicated that cell division and expansion had ceased in most of the soybean leaflets cells. Visual observations of leaf color indicated that leaf senescence had been initiated by DOY 242 for both water-stressed and well-watered plots.

A relationship between reflectance and transmittance properties and leaflet growth was observed (compare Fig. 2 and 3). Reflectance and transmittance in the visible wavebands generally decreased as leaflets developed and approached full expansion (ca. DOY 230). The trend was most clearly evident in the green spectral region (Waveband 2) (Fig. 3). For example, reflectance in the green spectral region from adaxial leaflet surfaces in well-watered soybeans decreased approximately $4 \%$ from initial reflectance values (approximately $27 \%$ relative decrease), while transmittance decreased by approximately $13 \%$ (approximately $65 \%$ relative decrease). Changes in reflectance and transmittance in the visible portion of the spectrum indicate pigment development. Cell organelles, such as chloroplasts, develop concurrently with mesophyll cell enlargement (Leech, 1985). As a result, absorption in the visible wavebands increased (i.e., reflectance and transmittance decreased) as full leaflet expansion was approached (ca. DOY 230). Reflectance and transmittance increased after leaflets were fully expanded and leaf yellowing was initiated as was similarly observed in cotton leaves (Gausman, 1982). Increased reflectance in the visible portion can be attributed to chlorophyll degradation, unmasking anthocyanin or carotene pigments in the blue and red bands (Gausman, 1985). 
Spongy mesophyll cells enlarge while palisade cells continue to divide and elongate (Decker and Postlethwait, 1961). Mesophyll intercellular spaces of $C_{3}$ species are assumed to form during the later stages of cell enlargement as epidermal cells expand causing the separation between leaf mesophyll cells (Digby and Firn, 1985). Near-infrared optical properties are a function of the number of intracellular refractive index discontinuities, which increase as the leaf develops (Gates, et al., 1965; Knipling, 1970; Woolley, 1971). Relative leaf growth estimates serve as indicators of internal structural changes. Near-infrared reflectance increased

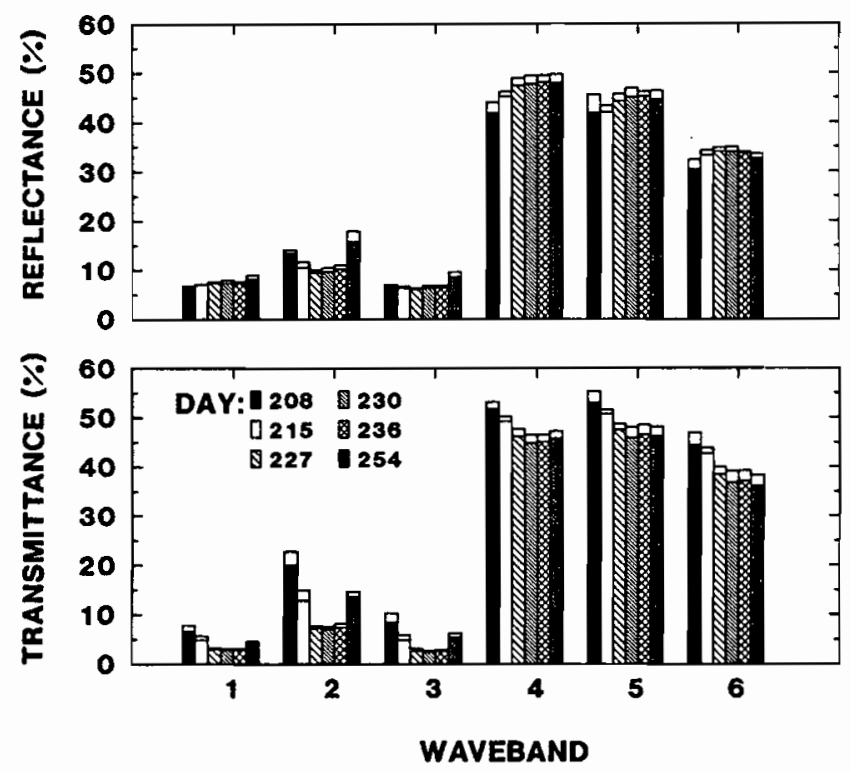

Fig. 3. Mean refiectance and transmittance of adaxial surface of well-watered soybean leaflet (Nodes 10 and 11 ) for selected days of the experimental period for Wavebands 1 through 6. Error bars (square) represent +1 standard deviation.
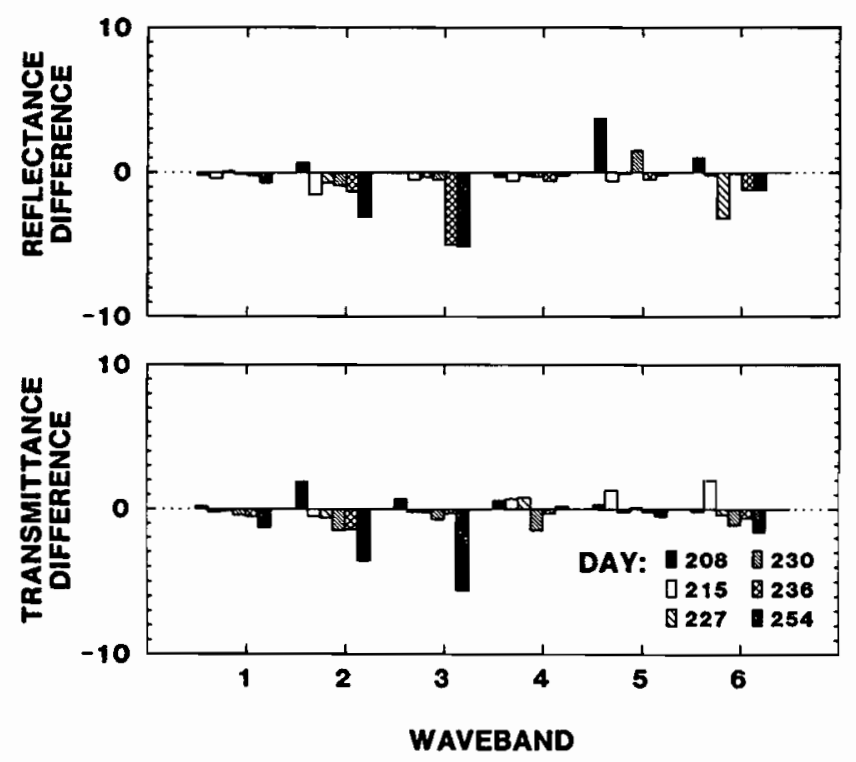

Fig. 4. Absolute difference (percent) between adaxial surfaces of wellwatered (WW) and water-stressed (WS) soybean leaflet (WW-WS) (Nodes 10 and 11 ) mean reflectance and transmittance on selected days of the experimental period for Wavebands 1 through 6. with leaf expansion, while visible reflectance decreased with leaf expansion. Similar changes in visible and NIR reflectances were observed in oak (Gates et al., 1965; Boyer et al., 1988) and cotton (Gausman et al., 1970). Near-infrared transmittance decreased when NIR reflectance from leaflet surfaces increased (Fig. 3). For example, in well-watered soybeans, NIR reflectance increased from approximately 42 to $48 \%$ (approximately $14 \%$ relative increase). Near-infrared transmittance through the same leaflet surfaces decreased from approximately 52 to $45 \%$ (approximately $13 \%$ relative decrease). Near-infrared reflectance and transmittance remained fairly constant following full leaf expansion while visible reflectance and transmittance increased. If more time had elapsed it is expected that NIR reflectance would have decreased and NIR transmittance would have increased as was reported for oak leaves (Boyer et al., 1988).

Slight and variable differences were detected between well-watered and water-stressed leaflet properties of similar surfaces (Fig. 4). The lack of variation is attributed to the similarity of leaflet growth (Fig. 2). Visible reflectance and transmittance of water-stressed leaflets typically were slightly higher than well-watered leaflets while differences varied in near- and mid-IR wavebands.

Differences in reflectance and transmittance properties between abaxial and adaxial soybean leaflet surfaces were observed in most wavebands (Fig. 5). Abaxial surfaces reflected and transmitted more in the visible and transmitted more in the NIR but reflected less in the NIR than adaxial surfaces. Differences were greatest for visible reflectance and NIR transmittance. The same trend in pattern and magnitude was observed in water-stressed leaflets. Differences in pubescence, cuticle thickness or chlorophyll distribution between the two leaflet surfaces could contribute to reflectance and transmittance differences in the visible
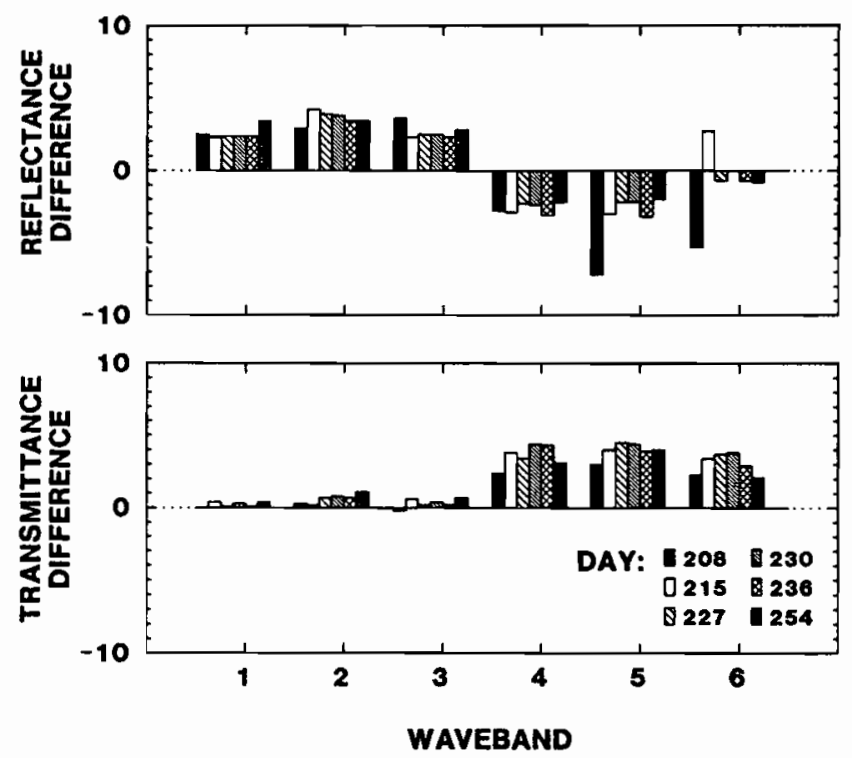

Fig. 5. Absolute difference (percent) between abaxial (AB) and adaxial (AD) well-watered soybean leaflet surface (AB-AD) (Nodes 10 and 11) mean reflectance and transmittance on selected days of the experimental period for Wavebands 1 through 6 . 
wavebands. Chlorophyll is generally more densely packed in the upper part of the leaflet mesophyll of dicotyledonous plants (Terashima and Saeki, 1983). Light absorption by chlorophyll concentrated in the upper leaf surface has been used to account for the lower reflectance from and transmittance through adaxial surfaces than from abaxial surfaces (Gausman, 1985). The difference in magnitude of NIR reflectance from upper and lower surfaces can be attributed to differences in light beam pathway between the palisade and spongy mesophyll layers. Air-cell wall interfaces can be as numerous or even more numerous in the palisade tissue as in the spongy mesophyll (Gausman et al., 1971a). The numerous interfaces in the palisade layer could account for the larger reflectance from adaxial surfaces than observed from abaxial surfaces (Woolley, 1971).

Corn. Mean spectral values varied little for midcanopy leaf surfaces during leaf emergence and the remaining experimental period in most wavebands except the green spectral band (Fig. 6). Near constant values in the near- and mid-IR wavebands were attributed to internal cell structure and the monocot leaf maturation process. The corn leaf basal meristem is enclosed by sheaths and upper leaf bases and is not exposed during growth and maturation (Dale and Milthorpe, 1983). Cells at the leaf tip become fully differentiated earlier than those at the base and will reach full maturity before basal meristem cells cease dividing (Dale and Milthorpe, 1983). The exposed portion of an emerging corn leaf will be fully expanded although cell division and expansion will continue inside the sheath. Near constant NIR reflectance and transmittance values indicated that the corn leaf structure was maintained throughout the experiment.

Chloroplast development apparently is concurrent with mesophyll cell enlargements (Leech, 1985). However, slight variations in reflectance and transmittance

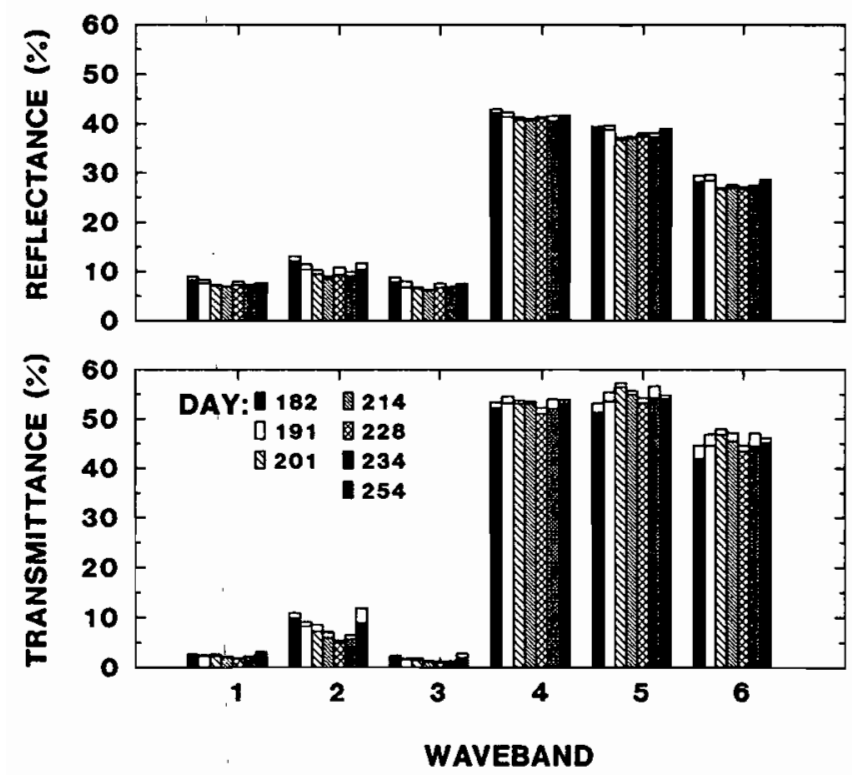

Fig. 6. Well-watered adaxial mid-canopy corn leaf surface (Nodes 11 and 12) mean reflectance and transmittance for selected days of the experimental period for Wavebands 1 through 6 . Error bars (ㅁ) represent +1 standard deviation. in the visible spectral region were observed that suggest a change in the content of chlorophyll and other pigments over time. For example, initial visible reflectance from adaxial mid-canopy corn leaves was $12 \%$ but decreased to approximately $9 \%$ at DOY 228 (approximately $22 \%$ relative difference). No color change was detected visually during the experimental period.

Slight differences in the reflectance from and transmittance through abaxial and adaxial surfaces were observed in mid-canopy corn leaves (Fig. 7). Similar comparable reflectances occurred in upper-canopy corn leaves. In monocots, concentric layers of bundle sheath cells surrounded by mesophyll cells predominate, while leaf palisade and spongy mesophyll tissue layers (upper and lower, respectively) are well defined in dicots. The present data indicated that the internal structural integrity of well-watered corn leaves is maintained over time. Also, little variation was observed in spectral properties between mid- and uppercanopy leaves (Fig. 8).

Comparison Between Soybean and Corn. Visible reflectance and transmittance properties of fully expanded, well-watered adaxial soybean leaflets were similar to those of adaxial corn leaf surfaces (compare Fig. 3 and 6). Visible reflectance and transmittance values were generally higher for immature soybean leaflets and those undergoing senescence than for mature corn leaves while NIR reflectance and transmittance values for immature soybean leaflets were similar to those values of corn leaves. The similarity is attributed to an internal compacted cellular structure for corn leaves and, at this time, soybean leaflets. Soybean NIR reflectance became greater than corn NIR reflectance while soybean NIR transmittance was lower than that of corn as soybean leaflets expanded. Soybean leaflet dorsiventral structure as compared to corn leaf compact structure probably contributes to
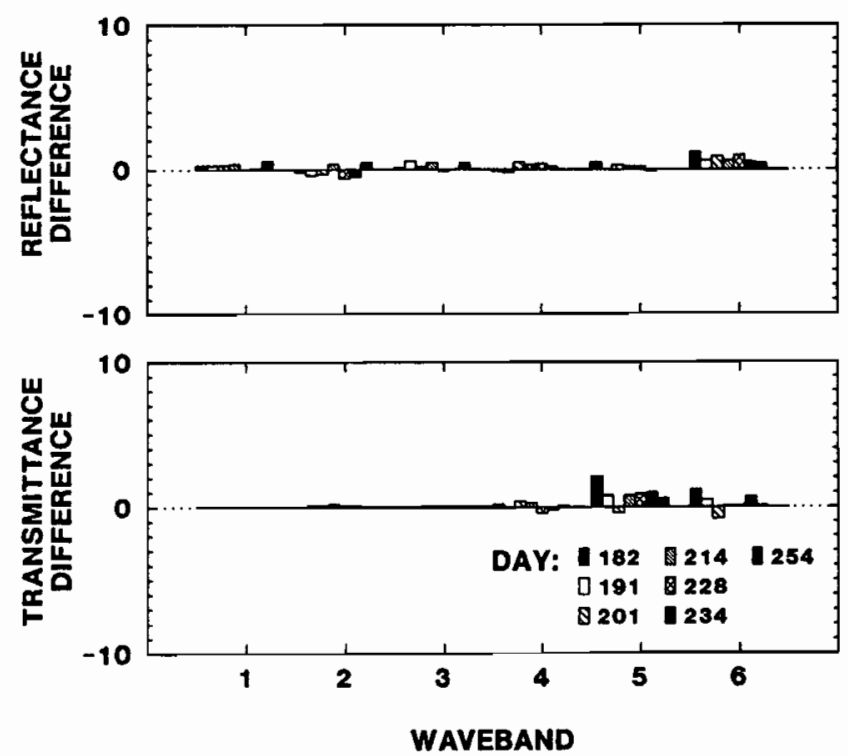

Fig. 7. Absolute difference (percent) between abaxial (AB) and adaxial (AD) well-watered mid-canopy corn leaf surface (AB-AD) mean reflectance and transmittance on selected days of the experimental period for Wavebands 1 through 6. 

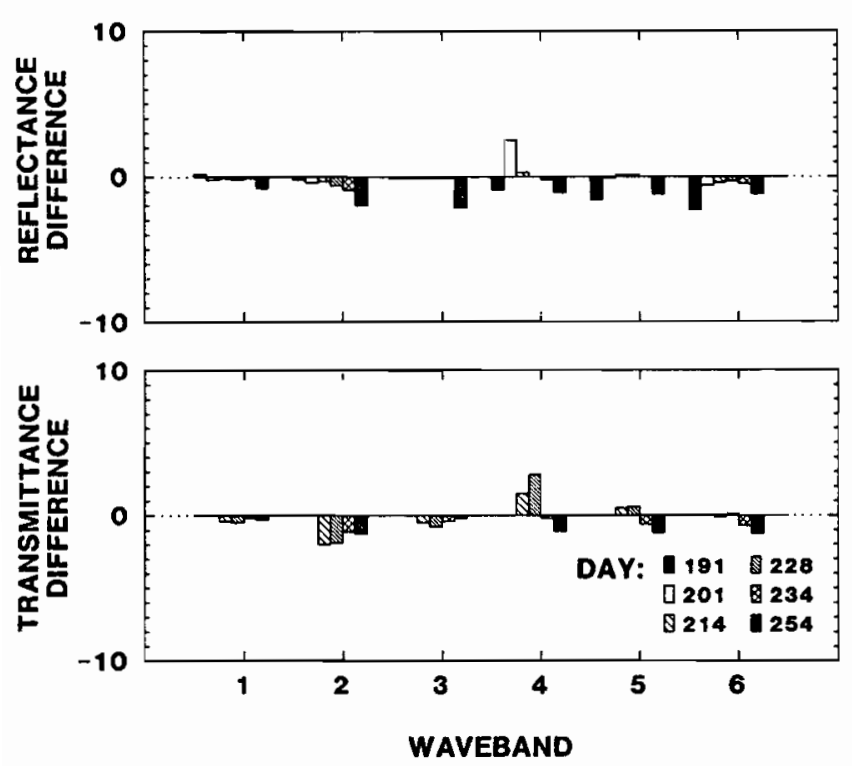

Fig. 8. Absolute difference (percent) between adaxial well-watered mid- and upper-canopy corn leaf surface (mid-upper) mean reflectance and transmittance for Wavebands 1 through 6 on selected days of the experimental period.

the higher reflectance and lower transmittance (Gausman, 1985).

\section{CONCLUSIONS}

Directional-hemispherical visible reflectance and transmittance at near-normal incidence decreased as soybean leaflets developed and approached full leaf expansion. Values increased after leaflets were fully expanded. The reverse occurred for NIR reflectance, but the change in NIR transmittance was similar to that in visible reflectance and transmittance over time. The magnitude of changes in soybean leaf reflectance from abaxial and adaxial surfaces over time may not be large, while transmittance differences can be large, particularly in the green spectral region. Slight and varied differences between optical properties of wellwatered and water-stressed soybean leaflets were most pronounced in the visible wavelength region during the latter part of the experiment. Soybean leaflets differed in reflectance and transmittance between abaxial and adaxial surfaces by approximately $5 \%$ (absolute difference) while corn leaf surface optical properties were nearly identical between surfaces. Spectral properties of exposed corn leaf surfaces remained fairly constant throughout the field experiment in all wavebands except the green waveband. Differences in reflectance and transmittance properties during soybean leaflet and corn leaf growth can be attributed to differences in cellular structure and maturation in dicots and monocots. Leaf optical property observations such as these presented may be critical in photosynthesis studies and crop canopy radiative transfer modeling, especially for simulations of a developing canopy. Reflectance and transmittance from adaxial and abaxial surfaces may have to be considered in modeling soybean canopies while only one surface should be suffcient to describe light interaction with corn canopy leaves.

\section{ACKNOWLEDGMENTS}

This research was supported by the National Aeronautics and Space Administration (NASA) Remote Sensing Science program, Grant no. NAG5-277. The authors wish to thank Cynthia Hays and Mark Mesarch for their assistance in the data reduction, statistics, and graphics.

\section{REFERENCES}

Boyer, M.. J. Miller, M. Belanger, and E. Hare. 1988. Senescence and spectral reflectance in leaves of Northern Pin Oak (Quercus palustris Muenchh.). Remote Sens. Environ. 25:71-87.

Dale, J.E., and F.L. Milthorpe. 1983. General features of the production and growth of leaves. p. 151-178. In J.E. Dale and F.L. Milthorpe (ed.) The growth and functioning of leaves. Cambridge University Press, New York

Decker, R.D., and S.N. Postlethwait. 1961. The maturation of the trifoliate leaf of Glycine max. Proc. Indiana Acad. Sci. 70:66-72.

Digby, J., and R.D. Firn. 1985. Growth substances and leaf growth. p. 57-76. In N.R. Baker, W.J. Davies, and C.K. Ong (ed.) Control of leaf growth. Cambridge Univ. Press, New York.

Gates, D.M., H.J. Keegan, J.C. Schleter, and V.R. Weidner. 1965. Spectral properties of plants. Appl. Optics 4:11-20.

Gausman, H.W. 1977. Reflectance of leaf components. Remote Sens. Environ. 6:1-9.

Gausman, H.W. 1982. Visible light reflectance, transmittance, and absorptance of differently pigmented cotton leaves. Remote Sens. Environ. 13:233-238.

Gausman, H.W. 1985. Plant Leaf Optical Properties in Visible and Near-Infrared Light. Graduate Studies no. 29, Texas Tech University. Texas Tech. Press, Lubbock, TX.

Gausman, H.W., and W.A. Allen. 1973. Optical parameters of leaves of 30 plant species. Plant Physiol. 52:57-62.

Gausman, H.W., W.A. Allen, R. Cardenas, and A.J. Richardson. 1970. Relation of light reflectance to histological and physical evaluations of cotton leaf maturity. Appl. Optics 9:545-552.

Gausman, H.W., W.A. Allen, R. Cardenas, and A.J. Richardson. 1971 a. Effects of leaf nodal position on absorption and scattering coefficients and infinite reflectance of cotton leaves, Gossypium hirsutum L. Agron. J. 63:87-91.

Gausman, H.W., W.A. Allen, D.E. Escobar, R.R. Rodriguez, and R. Cardenas. 1971b. Age effects of cotton leaves on light reflectance, transmittance, and absorptance and on water content and thickness. Agron. J. 63:465-469.

Grant, L., C.S.T. Daughtry, and V.C. Vanderbilt. 1987. Polarized and non-polarized leaf reflectances of Coleus blumei. Environ. Exp. Bot. 27:139-145.

Knipling, E.B. 1970. Physical and physiological basis for the reflectance of visible and near-infrared radiation from vegetation. Remote Sens. Environ. 1:155-159.

Leech, R.M. 1985. The synthesis of cellular components in leaves. p. 93-114. In N.R. Baker, W.J. Davies, and C.K. Ong (ed.) Control of leaf growth. Cambridge Univ. Press, New York.

Maas, S.J., and J.R. Dunlap. 1989. Reflectance, transmittance, and absorptance of light by normal. etiolated, and albino corn leaves. Agron. J. 81:105-110

Mesarch, M.A., Walter-Shea, E.A., B.F. Robinson, J.M. Norman, and C.J. Hays. 1991. Performance evaluation and operation of a field-portable radiometer for individual leaf optical measurements. AgMet Progress Report 9/-2, Department of Agricultural Meteorology, University of Nebraska, Lincoln, 68583-0728.

Palmer, J.W. 1977. Light transmittance by apple leaves and canopies. J. Appl. Ecol. 14:505-513.

Ross, J. 1981. The Radiation regime and architecture of plant stands. The Hague, Dr. W. Junk Publishers, Boston, MA.

Terashima, I., and T. Saeki. 1983. Light environment within a leaf I. Optical properties of paradermal sections of Camellia leaves with special reference to differences in the optical properties of palisade and spongy tissues. Plant Cell Physiol. 24:1493-1501.

Woolley, J.T. 1971. Reflectance and transmittance of light by leaves. Plant Physiol. 47:656-662. 

